\title{
UM SISTEMA SIMPLES PARA PREPARAÇÃO DE MICROESFERAS DE QUITOSANA
}

\author{
Francisco S. Dias e Danilo C. Queiroz \\ Departamento de Química Orgânica e Inorgânica, Universidade Federal do Ceará, 60451-970 Fortaleza - CE, Brasil \\ Ronaldo F. Nascimento* \\ Departamento de Química Analítica e Físico Química, Universidade Federal do Ceará, 60451-970 Fortaleza - CE, Brasil \\ Mario Bastos Lima \\ Parque de Desenvolvimento Tecnológico do Ceará, Rua do Contorno, s/n, Fortaleza - CE. Brasil
}

Recebido em 22/8/06; aceito em 18/5/07; publicado na web em 19/12/07

\begin{abstract}
SIMPLE SYSTEM FOR PREPARATION OF CHITOSAN MICROSPHERES. This article describes the construction and optimization of an inexpensive apparatus for the production of uniform and porous chitosan microspheres. It also describes the control of the main operational parameters and strategies for the production of uniform chitosan microspheres.
\end{abstract}

Keywords: porous beads; chitosan; chitosan microspheres.

\section{INTRODUÇÃO}

A quitosana é um derivado da quitina, biopolímero presente nas carapaças dos crustáceos, nos exoesqueletos dos insetos e nas paredes celulares de fungos ${ }^{1,2}$. A quitina é constituída de unidades 2-acetamido-2-desoxi-D-glicopiranose unidas por ligações $\beta$ $(1 \rightarrow 4)$ e quando desacetilada, quer seja por tratamento com bases fortes quer seja por métodos microbiológicos, resulta na estrutura $\beta$-(1 $\rightarrow 4)$-2-amino-2-desoxi-D-glicopiranose, conhecida como quitosana $^{1,2}$.

As propriedades da quitosana, como viscosidade, grau de desacetilação, massa molar dependem das fontes de matéria-prima e métodos de fabricação. O grau de desacetilação, uma das mais importantes propriedades químicas desse polímero, determina a quantidade de grupos amínicos na cadeia polimérica, sendo que, uma extensão acima de $60 \%$ de desacetilação, define a entidade química quitosana ${ }^{2,3}$.

A quitosana nas formas de pó ou de flocos tem sido muito utilizada em processos de adsorção de íons metálicos ${ }^{3-10}$ e corantes $^{11-13}$. Todavia, nestas formas a quitosana apresenta duas grandes desvantagens: solubilidade em meio ácido, que dificulta sua recuperação, e baixa área superficial, que limita o acesso aos sítios de adsorção (grupos amino) não expostos, diminuindo a velocidade e a capacidade de adsorção. Estes problemas podem ser contornados, respectivamente, promovendo-se a reticulação da cadeia polimérica da quitosana e sua modificação física, da forma de pó ou floco para a forma de esferas ${ }^{14-19}$.

A produção de esferas de quitosana juntamente com a sua funcionalização propiciam a obtenção de um material com elevada capacidade de adsorção de íons metálicos, como tem sido demonstrado em diversas pesquisas ${ }^{20-27}$.

$\mathrm{Na}$ literatura, diferentes métodos descrevendo o processo de preparação de microesferas de quitosana têm sido publicados, tais como atomização ${ }^{28,29}$, emulsão $0^{30,31} \mathrm{e}$ inversão de fase ${ }^{32}$. Neste trabalho, as microesferas de quitosana foram preparadas pelo método de inversão de fase baseado no trabalho de Rorrer ${ }^{32}$. Entretanto, a confecção reprodutível de microesferas de quitosana porosas e uniformes por esse método depende do controle dos parâmetros:

*e-mail: ronaldo@ufc.br velocidade do fluxo de gotejamento da solução de quitosana, velocidade do fluxo de ar, diâmetro da agulha do gotejador, espaço anular (espaço entre ponta da agulha do tubo ao tubo de saída de ar) e a altura do gotejador em relação à superfície da solução coagulante, bem como da densidade da solução coagulante ${ }^{33}$. Assim, o objetivo deste estudo foi adaptar e aperfeiçoar um processo de baixo custo para a confecção reprodutível de microesferas de quitosana porosas e com tamanhos uniformes.

\section{PARTE EXPERIMENTAL}

\section{Reagentes e materiais}

A quitosana utilizada no estudo foi cedida pela empresa Polymar S/A, com as seguintes características físico-químicas: granulometria 80 mesh, grau de desacetilação $93 \%$ determinado por titulação potenciométrica, $\mathrm{pH}$ 7,8 (água de lavagem da quitosana), densidade $0,40 \mathrm{~g} / \mathrm{mL}$, massa molar média da quitosana de aproximadamente $69.000 \mathrm{~g} / \mathrm{mol}$ e viscosidade da solução de quitosana $(4 \% \mathrm{~m} /$ v), em ácido acético $(5 \% \mathrm{~m} / \mathrm{v})$, de $630 \mathrm{cps}$ (Brookfield, Modelo DV-II+, LV Spindle S a $29^{\circ} \mathrm{C}$, USA). Ácido acético e hidróxido de sódio de grau analítico (Vetec, São Paulo).

\section{Otimização da metodologia de preparação das microesferas de quitosana}

\section{Preparação da solução e de microesferas de quitosana}

Quitosana (4 g) foi dissolvida em $1 \mathrm{~L}$ de solução de ácido acético $(5 \% \mathrm{~m} / \mathrm{v})$ contendo acetato de sódio na proporção de 1:1 em relação à quantidade de quitosana adicionada. A solução foi inicialmente filtrada em tela de aço inox 40 mesh.

A solução assim obtida foi gotejada sobre uma solução de hidróxido de sódio $8 \%(\mathrm{~m} / \mathrm{v})$ com o auxílio de uma bomba peristáltica e um compressor de ar. As microesferas de quitosana permaneceram na solução de hidróxido de sódio $8 \%(\mathrm{~m} / \mathrm{v})$ sob agitação mecânica por $16 \mathrm{~h}$ e depois foram lavadas com água destilada até pH 7,5.

\section{Determinação do diâmetro médio das microesferas}

$\mathrm{O}$ diâmetro médio das microesferas de quitosana foi determinado pela medida de 40 microesferas em micrômetro óptico (Baush 
\& Lomb, USA), acoplado a microscópio estereoscópio Taimin TE 1L (ampliação: 1x). Uma segunda alternativa, de baixo custo, para medir o diâmetro médio das microesferas de quitosana, seria via utilização de um paquímetro e um microscópio estereoscópio, da seguinte forma: coloca-se o microscópio estetoscópio com fundo preto e algumas microesferas espalhadas (olhando pela ocular bem focalizada) e utiliza-se um paquímetro de modo a medir individualmente cada microesfera de quitosana, num total significativo de amostras (40 ou mais). É importante não apertá-la muito com o paquímetro. Para avaliação morfológica das microesferas de quitosana utilizou-se a técnica de microscopia eletrônica de varredura (MEV, Philips modelo SEM - XL30).

Descrição do sistema de preparação de microesfera de quitosana

O sistema prático para produção de microesfera de quitosana foi construído tal qual como descrito a seguir: o gotejador foi inicialmente construído tomando como base um esquema apresentado por Rorrer e colaboradores ${ }^{32}$ e detalhes que não foram relatados pelos autores no trabalho inicial. Neste foi usado vidro borossilicato e uma agulha hipodérmica comercial (aço inox). A Figura 1 mostra em detalhes a construção do gotejador, o qual consta de três partes: um tubo de vidro interno (180 $\mathrm{mm}$ de comprimento total) com extremidade cônica esmerilhada para o encaixe de uma agulha hipordémica comercial; um tubo de vidro externo $(150 \mathrm{~mm})$ com saída lateral para a entrada de ar comprimido e com uma redução $(4 \times 15 \mathrm{~mm})$ na extremidade, a agulha hipodérmica comercial, que pode ser intercambiada com outras de diâmetros variados $(0,4 ; 0,6 ; 0,8$ ou $0,9 \mathrm{~mm})$.

O tubo de vidro interno (que contém a agulha) é fixado e centralizado através de um adaptador rosqueável de polietileno, idêntico aos usados para fixação de termômetros em juntas de vidro esmerilhadas. A agulha hipodérmica comercial tem sua ponta desbastada e polida em lixa de água 150 e 220.

A posição final da agulha deve ficar centralizada e ultrapassando a extremidade da redução em 3,0 mm (espaço anular).

O banho coagulante fica em uma cuba de vidro borossilicato sob agitação constante e suave, através de uma haste com hélice de vidro acoplada a um motor por indução magnética sem faiscamento, como ilustrado na Figura 2.

A solução de quitosana pode ser levada lentamente ao gotejador por gravidade através de um tubo de látex conectado a um funil de separação elevado a $15 \mathrm{~mm}$ de altura do gotejador. O uso de uma

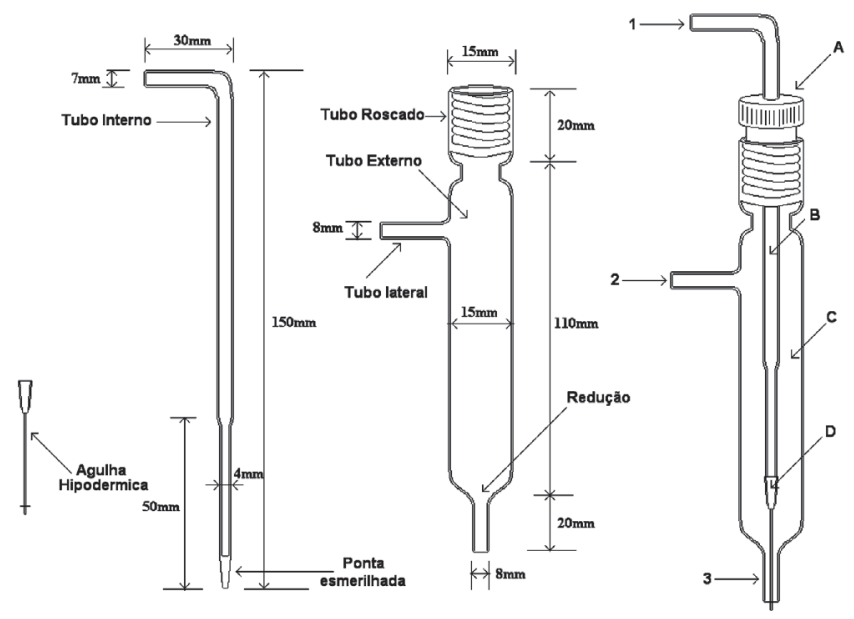

Figura 1. Esquema do gotejador. (A) Adaptador de polietileno; (B) tubo de vidro interno, $(C)$ tubo de vidro externo, (D) agulha hipordérmica. 1- Entrada da solução; 2-entrada de ar; 3- saída de ar bomba peristáltica, com controle sensível de fluxo, acelera o processo em mais de $30 \%$. O fluxo de ar pode ser fornecido por um mini-compressor de ar direto (fluxo descontínuo) controlado através de rotâmetro ( 7 L/min). O uso de gás $\mathrm{N}_{2}$ ou Ar apresenta um melhor desempenho por ter fluxo contínuo.

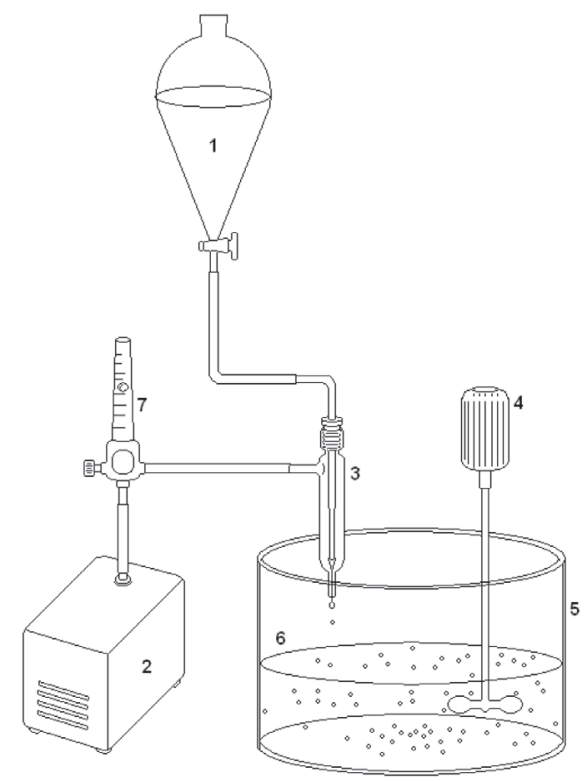

Figura 2. Esquema do sistema de preparação das miscroesferas de quitosana. 1 - Funil com solução de quitosana, 2 - bomba de ar comprimido; 3 gotejador, 4 - agitador (motor com hélice de vidro); 5 - cuba de vidro; 6 solução coagulante e 7 - rotâmetro

\section{Sistema para neutralização das microesferas}

Após a preparação das microesferas de quitosana é necessária a sua neutralização para posterior reticulação e/ou modificação química. A Figura 3 descreve um sistema simples utilizado para a "lavagem" das mesmas. Através de uma bomba peristáltica a água destilada contida em um frasco de Marriott de $18000 \mathrm{~mL}$ é bombeada para uma coluna onde estão as microesferas de quitosana aprisionadas. O fluxo de água ascendente promove uma movimentação contínua das partículas retirando a solução alcalina de dentro destas. A água destilada é trocada onstantemente até atingir pH 7,5.

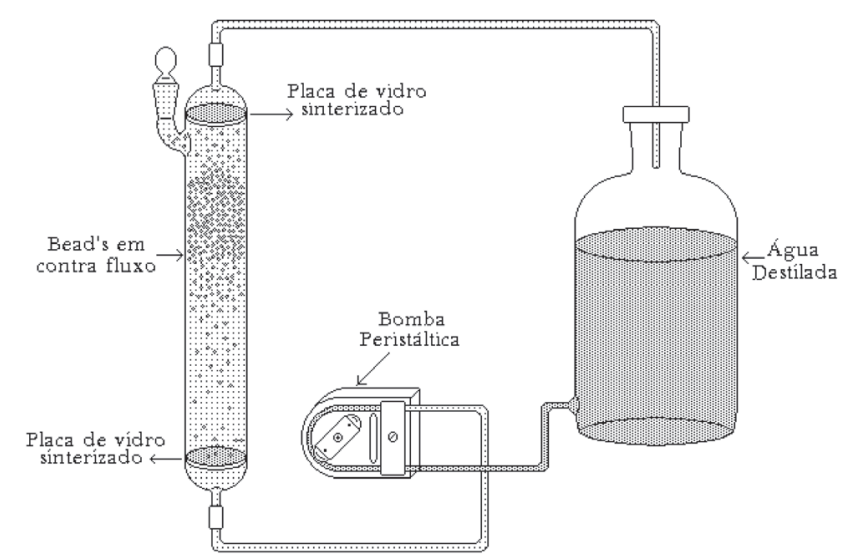

Figura 3. Sistema para neutralização das microesferas de quitosana por lavagem com água destilada em fluxo ascendente 


\section{RESULTADOS E DISCUSSÃO}

\section{Otimização do processo de preparação das microesferas de quitosana}

\section{Solução de quitosana}

A solução de quitosana adequada para sua conversão à forma de microesferas deve ser inicialmente diluída em baixas concentrações $(1-5 \% \mathrm{~m} / \mathrm{v})$, normalmente em ácido fórmico ou acético, cuja concentração de quitosana seja suficiente para a solução atingir uma viscosidade entre $340-630 \mathrm{cps}$ a $29{ }^{\circ} \mathrm{C}$ e possuir uma densidade adequada. A viscosidade da solução está diretamente relacionada à massa molar média da quitosana ${ }^{2,34,35}$.

Várias tentativas de otimização da produção de microesferas de quitosana foram realizadas para se obter uma relação ótima de viscosidade - densidade para a solução de quitosana usada neste trabalho. Esta relação foi elaborada preparando-se soluções com diferentes concentrações e, em seguida, testando-as no sistema. Os resultados observados indicaram que solução de baixa viscosidade produz microesferas de quitosana na forma de conchas e com baixa resistência mecânica; solução muito viscosa produz microesferas com cauda e com alta resistência mecânica; solução com viscosidade moderada produz microesferas sem cauda e com boa resistência mecânica.

Com relação à otimização da densidade da solução de quitosana, foram testados diversos tipos de sais (cloreto de sódio, cloreto de potássio, cloreto de cálcio, cloreto de magnésio e acetato de sódio). Estes foram adicionados à solução de ácido acético, em diferentes concentrações. O sal que apresentou o melhor resultado na correção da densidade da solução polimérica foi o acetato de sódio na proporção quitosana:acetato de sódio $(1: 1)^{33}$. Para diminuir os custos da preparação das microesferas de quitosana, optou-se por gerar o acetato de sódio in situ, a partir de reagentes mais baratos (hidróxido de sódio e ácido acético), em vez de utilizar o reagente P.A.

\section{Solução coagulante}

A formação de microesferas de quitosana se dá pela neutralização da solução ácida de quitosana por uma base forte, tipicamente $\mathrm{NaOH}$ ( 8 a $10 \% \mathrm{~m} / \mathrm{v}$ ). Esta solução coagula a quitosana no formato das gotas. Este mecanismo promove a formação de microesferas que ficam em suspensão na solução coagulante com ajuda de uma agitação mecânica lenta. A uniformidade e esfericidade das partículas de quitosana são conseguidas ajustando-se a altura de queda das gotas, a velocidade de agitação e a densidade da solução de quitosana, que deverá ser ligeiramente superior à da solução coagulante. Neste mecanismo, quando uma gota atinge a superfície da solução coagulante com densidade maior que a solução de quitosana, a gota choca-se com a solução alterando seu formato esférico, mergulhando na solução com geometria irregular. Entretanto, para o caso ideal, onde a relação entre as densidades é próxima de 1:1, quando a gota atinge a superfície do líquido ela não deforma e mergulha totalmente completando a coagulação de modo uniforme. Uma estratégia eficiente para ajustar a densidade da solução de quitosana (como já mencionado) é a adição de acetato de sódio ${ }^{33}$.

\section{Funcionamento e otimização do sistema de produção de microesferas}

A solução de quitosana deve ser filtrada em tela de aço inox com malhas de 40 mesh, em seguida adicionada ao funil de separação, que é elevado para que a solução escoe no tubo de látex, por gravidade até o gotejador. As gotas que se formam crescem em tamanho até caírem com o próprio peso. A injeção de ar flui paralelamente à agulha e arrasta a gota, impedindo que esta cresça. Quanto menor o fluxo de ar menor a força de arraste, permitindo um maior crescimento da gota e, consequentemente, uma microesfera de diâmetro maior. O fluxo da solução de quitosana pode ser regulado por uma pinça de Mohr, apertando, ou seja, estrangulando o tubo de látex que alimenta o gotejador. Quando a solução está com viscosidade ideal este ajuste é desnecessário. Entretanto, com bomba peristáltica o fluxo pode ser regulado de modo a acelerar o processo (4,0-10 $\mathrm{mL} / \mathrm{min})$. No entanto, um fluxo muito elevado pode formar microesferas com cauda. A regulagem anular (espaço entre a ponta da agulha ao tubo de saída de ar) ajusta a forma de contato do ar com a superfície da gota, ajustando-se sua esfericidade; quanto menor o espaço anular mais turbulento é o fluxo de ar, resultando em partículas ovais. Para as dimensões deste protótipo este valor está em torno $3,0 \mathrm{~mm}$, ponto onde o fluxo de ar é laminar. A distância da superfície da solução coagulante à ponta da agulha deve ser ajustada para reduzir o choque da gota contra a superfície ${ }^{33}$. A perfeita geometria esférica da partícula é conseguida pelo ajuste de todo o conjunto, ou seja, fluxo de solução, fluxo de ar, diâmetro da agulha, espaço anular e altura do gotejador em relação à solução coagulante.

O rendimento deste processo é avaliado pela capacidade de conversão de solução a microesferas de quitosana uniformes. Como quase toda a solução de quitosana (geralmente, há perdas durante o processo da solução viscosa na tubulação) é convertida em microesferas, este rendimento está em torno de 99,9\%.

O aumento da velocidade do processo de produção de microesferas de quitosana pode ser conseguido aumentando-se o número de agulhas hipodérmicas no sistema.

\section{Tamanho e morfologia das microesferas de quitosana.}

As microesferas de quitosana úmidas, secas e re-hidratadas

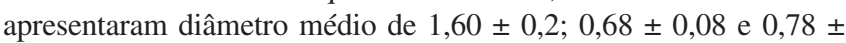
$0,14 \mathrm{~mm}$, respectivamente. Destas, aproximadamente $85 \%$ das produzidas secas encontram-se com tamanho de 0,68 $\pm 0,08 \mathrm{~mm}$, as quais foram reservadas para a realização dos estudos de adsorção subseqüentes. A Figura 4a apresenta uma microfotografia na qual se observam os tamanhos e as formas de algumas microesferas de quitosana secas. Nota-se que algumas delas não são perfeitamente esféricas, apresentando formatos ovais. Em relação à porosidade, são observadas cavidades em sua superfície bastante irregulares

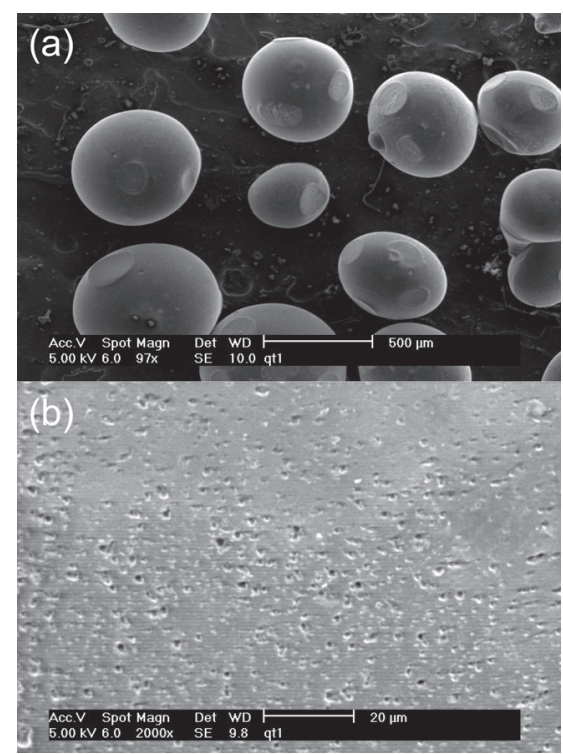

Figura 4. Microfotografia das microesferas de quitosana (a). Porosidade externa média de uma microesfera de quitosana $(b)$ 
em suas formas e tamanhos (Figura 4b), não sendo possível estimar um tamanho médio para os poros das microesferas de quitosana sem incorrer em grandes erros estatísticos.

\section{CONCLUSÕES}

O sistema desenvolvido para produção de microesferas de quitosana é reprodutível, em escala de laboratório, e funciona perfeitamente. Microesferas úmidas foram obtidas com diâmetro médio de 1,60 \pm 0,26 mm, controlando-se os parâmetros velocidade do fluxo de gotejamento da solução de quitosana, velocidade do fluxo de ar, diâmetro da agulha e altura do gotejador em relação à superfície da solução coagulante, bem como a sua densidade. No momento este processo está sendo utilizado para produção de microesferas de quitosana em maior escala, as quais estão sendo usadas para estudo de adsorção de metais, de óleos e liberação de fármacos.

\section{AGRADECIMENTOS}

Ao CNPq, CAPES e FUNCAP pelo suporte com bolsas, e ao PADETEC pela disponibilização da infra-estrutura laboratorial.

\section{REFERÊNCIAS}

1. Muzzarelli, R. A. A.; Chitin, $1^{\text {st }}$ ed., Pergamon Press Ltd: Oxford, 1978.

2. Roberts, G. A.; Chitin Chemistry, $1^{\text {st }}$ ed., MacMillan Press Ltd: Hong Kong, 1992.

3. Guibal, E.; Sep. Purif. Technol. 2004, 38, 43.

4. Eiden, C. A.; Jewell, C. A.; Wightman, J. P.; J. Appl. Polym. Sci. 1980, 25, 1587.

5. Maruca, R.; Suder, B. J.; Wightman, J. P.; J. Appl. Polym. Sci. 1982, 27, 4827.

6. Sag, K.; Aktay, Y.; Process Biochem. 2001, 36,1187.

7. Ruiz, M.; Sastre, A.; Zikan, M. C.; Guibal, E.; J. Appl. Polym. Sci. 2001, 81,153 .

8. Juang, R. S.; Shao, H. J.; Water Res. 2002, 36, 2999.

9. Ng, J. C. Y.; Cheung,W. H.; McKay,G.; J. Colloid Interface Sci. 2002, 255 , 64
10. Klug, M.; Sanches, M. N. M.; Laranjeira, M. C. M.; Rodrigues, C. A.; Fávere, V. T.; Quim. Nova 1998, 21, 410.

11. Kimura, I. Y.; Gonçalves Jr, A. C.; Stolberg, J.; Laranjeira, M. C. M.; Fávere, V. T.; Polímeros 1999, 9, 51

12. Lima, I. S.; Ribeiro, E. S.; Airoldi, C.; Quim. Nova 2006, 29, 501.

13. No, H. K.; Meyers, S. P.; Rev. Environ. Contam. Toxicol. 2000, 163, 1.

14. Hsien, T. Y.; Rorrer, G. L.; Ind. Eng. Chem. Res. 1997, 36, 3631.

15. Tseng, R. L.; Wu, F. C.; Juang, R. S.; J. Chem. Technol. Biotechnol. 1999, $74,533$.

16. Becker,T.; Schlaak, M.; Strasdeit, H.; React. Funct. Polym. 2000, 44, 289.

17. Lee, S. T.; Mi, F. L.; Shen,Y. J.; Shyu, S. S.; Polymer 2001, 42, 1879.

18. Cao, Z.; Ge, H.; Lai, S.; Eur. Polym. J. 2001, 37, 2141.

19. Wan Ngah, W. S.; Endud, C. S.; Mayanar, R.; React. Funct. Polym. 2002, 50,181 .

20. Weltrowski, M. B.; Martel, M.; Morcellet, M.; J. Appl. Polym. Sci. 1996, $59,647$.

21. Guibal, E.; Milot, C.; Tobin, J. M.; Ind. Eng. Chem. Res. 1998, 37, 1454

22. Inoue, K.; Yoshizuka, K.; Ohto, K.; Anal. Chim. Acta 1999, 388, 209.

23. Qian, S.; Huang, G.; Jiang, J.; He, F.; Wang, Y.; J. Appl. Polym. Sci. 2000, $77,3216$.

24. Barros, F. C. F.; Sousa, F. W.; Cavalcante, R. M.; Carvalho, T. V.; Dias, F. S.; Queiroz, D. C.; Vasconcellos, L. C. G.; Nascimento, R. F.; CLEANSoil, Air, Water, no prelo.

25. Laus, R.; Laranjeira, M. C. M.; Martins, A. O.; Fávere,V. T.; Pedrosa, R. C.; Benassi, J. C.; Geremias, R.; Quim. Nova 2006, 29, 34.

26. Leite, F.; Modesto, C. M. D.; Nascimento, R. F.; Dias, F. S.; Rev. Iber. Polim. 2005, 6, 213.

27. Barros, F. C. F.; Cavalcante, R. M.; Carvalho,T. V.; Dias, F. S.; Queiroz, D. C.; Vasconcellos, L. G.; Nascimento, R. F.; Rev. Iber. Polim. 2006, 7, 232.

28. Torres, M. A.; Vieira, R. S.; Beppu, M. M.; Santana, C. C.; Polímeros 2005, 15, 306.

29. Mi, F. L.; Wong, T. B.; Shyu, S. S.; Chang, S. F.; J. Appl. Polym. Sci. 1999, 71,747

30. He, P.; Davis, S. S.; Illum, L.; Int. J. Pharm. 1999, 187, 53.

31. Singla, A. K.; Dhawan, S.; Biotech. Histochem. 2003, 78, 243.

32. Rorrer, G. L.; Hsien, T. -Y.; Way, J. D.; Ind. Eng. Chem. Res. 1993, 32, 2170 .

33. Lima, M. B.; Monografia, Universidade Federal do Ceará, Brasil, 2001.

34. Kamura, Y.; US Pat. 833, 237, 1989.

35. Canella, K. M N. de C.; Garcia, R. B.; Quim. Nova 2001, 24, 13.

36. Modesto, C. M. D.; Monografia, Universidade Federal do Ceará, Brasil, 2003. 